\title{
A NEW AND PRIMITIVE RETROBURSAL PLANARIAN FROM AUSTRALIAN FRESH WATERS (PLATYHELMINTHES, TURBELLARIA, TRICLADIDA)
}

\author{
by
}

IAN R. BALL

Institute of Taxonomic Zoology, University of Amsterdam, The Netherlands

\begin{abstract}
A primitive freshwater planarian, Eviella bynesae gen. et sp. nov. is described from Australia. It is characterized by its lack of eyes and pigment, possession of caudally branched oviducts, and fully fused testes. Although a primary bursa is absent, its function being taken over by the modified female genital canal, the female copulatory system is posterior to the male system. Despite this maricolan feature, and other similarities with primitive southern hemisphere freshwater planarians that have been classified in the Maricola, the present species is placed in the family Dugesiidae of the Paludicola. Evidence from its sensory organs suggests that it belongs on the main evolutionary line from which the majority of Australasian freshwater planarians have been derived.
\end{abstract}

\section{INTRODUCTION}

Among a collection of aquatic planarians from Australia made by Professor H. B. N. Hynes, and Professor W. D. Williams, and described in an earlier series of publications (Ball, 1974b, 1974c, 1977), there occurred a sample of unpigmented and blind specimens from the gravel bed of the River Howqua in the State of Victoria. These specimens, representing a hitherto undescribed species, showed a number of especially primitive features that made their study particularly interesting and difficult. In the present paper a new genus is erected to contain the new species to be described, and a detailed anatomical account, and systematic discussion, of the material is given.

\section{MATERIALS AND METHODS}

Details concerning the source and present locations of the specimens are given under the appropriate species heading below. The specimens were killed in Steinmann's fluid (Steinmann \& Bresslau,
1913 ) and fixed in $70 \%$ ethanol. For anatomical observations, selected specimens were embedded in paraffin in the usual way and serially sectioned at $8 \mu \mathrm{m}$ intervals. The sections were mounted on $75 \times 50 \mathrm{~mm}$ glass slides, the first section on each slide being in the upper left-hand corner when the slide label is to the right. Frontal sections were arranged with the ribbons running horizontally; the sagittal and transverse sections were arranged with the ribbons vertical. The sections were stained with Mallory-Heidenhain stain, or with Phosphotungstic Acid Haematoxylin, and were mounted in DPX. Any variations in these procedure are noted at the appropriate place in the text.

\section{SYSTEMATIC SECTION}

Family DUGESIIDAE Ball, 1974a

Eviella gen. nov.

Unpigmented Dugesiidae, without eyes, with one pair of anterior sensory pits. Female copulatory organs posterior to the male copulatory organs. Oviducts enter the female genital duct (bursal canal) separately from the sides, and each has a caudal branch. Vasa deferentia enter the penis bulb separately from the sides. Testes fused, predominantly ventral, and throughout the body length. With one gonopore. Cocoon unknown. Type species: Eviella bynesae sp. nov.

The genus is named for Dr. Eveline Marcus of São Paulo in recognition of her major contributions to invertebrate zoology, and as a mark of my personal gratitude and affection. 
Eviella hynesae sp. nov.

Type material. - Department of Entomology and Invertebrate Zoology, Royal Ontario Museum, Toronto, Canada. Holotype: sagittal sections on five slides (ROM C94a). Paratypes: sagittal sections on three slides (ROM C94b), frontal sections on four slides (ROM C94c), transverse sections on five slides (ROM C94d; an error was made in mounting these sections, but the correct order has been marked on each slide), several entire specimens in alcohol (ROM C94). Further paratypes have been retained in my private collection.

Description. - General features (fig. 1): Maximum size of preserved animals $6 \times 2.2 \mathrm{~mm}$. Totally devoid of pigment; without eyes. Body broad and leaf-like, very flat at the margins but with a plump or rounded cross-section medially. The head is rounded, with a slight point or projection in the mid-line, and without definite auricles. Just behind the anterior margin there are two deep ciliated pits, one on each side. In life it is probable that this species is most similar to Opisthobursa mexicana as figured by Mitchell \& Kawakatsu (1972: 3, fig. 1).

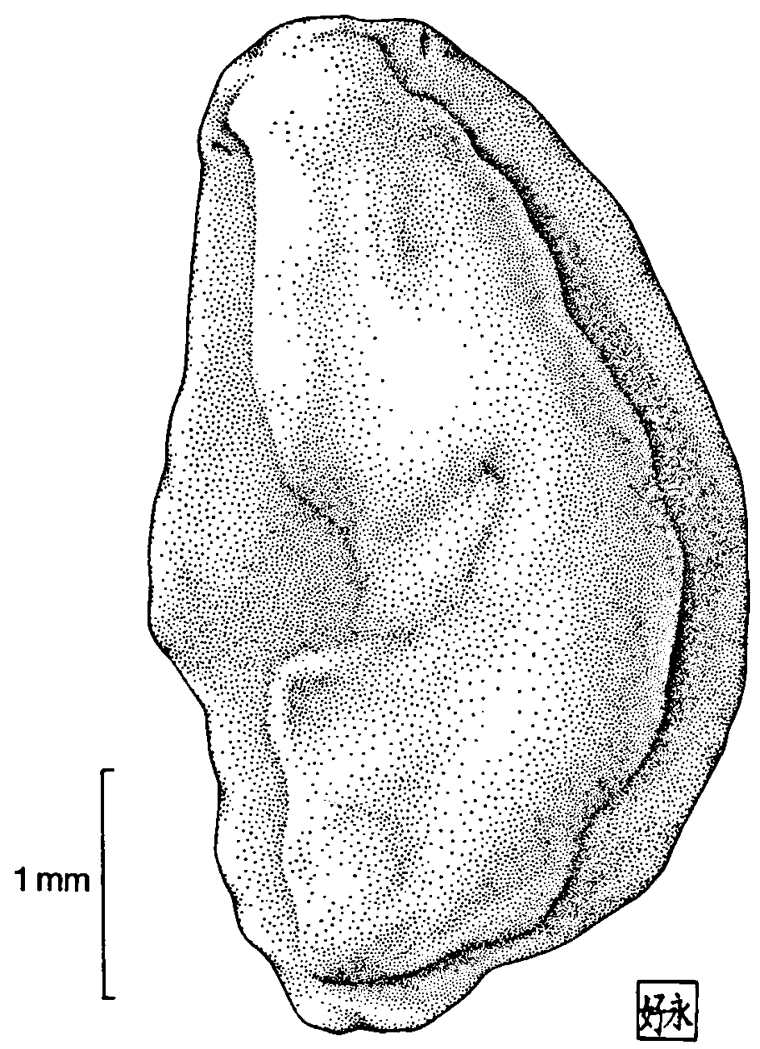

Fig. 1. Eviella bynesae gen. et sp. nov. External features drawn from a preserved specimen.
Alimentary system: For a body length of 100 the root of the pharynx is at about 45 and its tip at 66. Thus the pharynx is about one fifth of the body length and is inserted a little less than halfway down the body. The histological structure of the pharynx is basically the same as that of the marine and lower freshwater planarians (Kenk, 1930; Ball, 1974a) viz., the inner musculature consists of distinct circular and longitudinal fibrous zones. The anterior ramus of the intestine ends blindly as a group of small diverticula situated anteriorly to the brain; otherwise there are no noteworthy peculiarities of this system. A communication between the intestine and the reproductive system is not present.

Body wall (fig. 3): In its general structure the body wall is similar to that described for other Australasian planarians (Weiss, 1910; Ball, 1974b, 1974c). Eosinophilic gland cells, discharging through the epidermis, are very prominent just beneath the flattened anterior margin and are distributed in two longitudinal zones far distant from the lateral margins, there being one strip of such cells on each side of the mid-line. Marginal adhesive zones are common in aquatic planarians (Hyman, 1951) but such a medial position is unusual.

Sense organs (fig. 1): Although eyes are lacking, there remain two types of sensory organs in this species, the ciliated pits, and the sensory fossae. The ciliated pits are broad and deep invaginations of the body wall, one on each side (fig. 1) on the slightly projecting lateral margins of the head. Their tall nucleate epithelium is free of rhabdites and clothed in long cilia. Histologically they are identical with those described for other Australasian planarians (Weiss, 1910; Ball, 1974b, 1974c, 1977). The sensory fossae are of especial interest because all hitherto described freshwater planarians from Australia possess these structures. In the present species there are two shallow sensory fossae on each side of the anterior margin between the ciliated pits and the mid-line. They are identical to those described in many species of the genus Spathula, the most diverse genus in the Australasian region (Ball, 1977). 


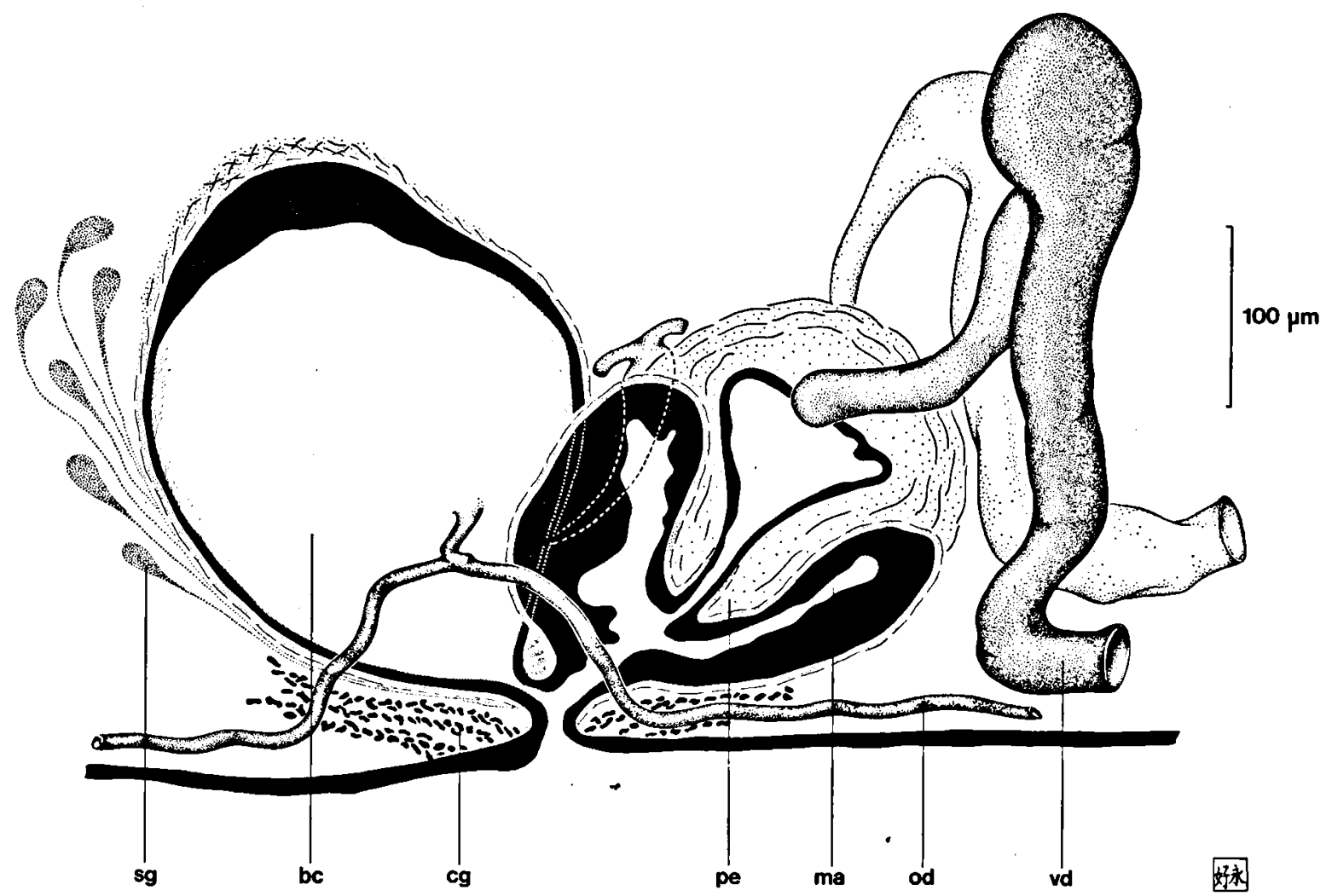

Fig. 2. Eviella bynesae gen. et sp. nov., holotype. Sagittal reconstruction of the copulatory apparatus viewed from the right side. $b c=$ "bursa copulatrix"; $c g=$ cement glands; $m a=$ male atrium; of = right oviduct; pe = penis; sg = shell glands; vd $=$ right vas deferens.

Male reproductive system (figs. 2-3): The testes of this species are unusual. Normal follicular testes are absent, instead there is a ramified system of fused testes, packed with sperm, that extend throughout the expanded part of the body, commencing just behind the ovaries. Although the testes are predominantly ventral in position (fig. 3) they frequently extend between and around the intestinal branches. The boundary of the male gonads within the mesenchyme is often difficult to delimit and spermatogonia, spermatids, and mature sperm seem frequently to be indiscriminantly scattered throughout the body, the sperm forming long sinuous strands (fig. 3 , te).

The male atrium is a large cavity, opening ventrally by a single gonopore which is surrounded by cement glands. The walls of the atrium are formed from a tall nucleate epithelium bounded by circular and longitudinal muscle fibres. The penis consists of a muscular hemispherical bulb and a conical papilla that projects into the male atrium. In the pharyngeal region the vasa deferentia become swollen and immediately anterior to the copulatory apparatus they ascend almost vertically before bending ventrad to enter the penis bulb separately from the sides; there is no common vas deferens. Within the bulb, the vasa deferentia open into a spacious seminal vesicle that narrows to form an ejaculatory duct opening at the tip of the papilla. Together the seminal vesicle and the ejaculatory duct have the form of a conical flask with slightly concave walls so that in sagittal section the seminal vesicle has a peculiar triangular form, as in the recently described Opistbobursa josephinae (Benazzi, 1976). All the epithelia of the male copulatory organ are fairly tall, and all are nucleate (fig. 3A).

Female reproductive system (figs. 2-3): The paired ovaries are ventrally situated, medially to 


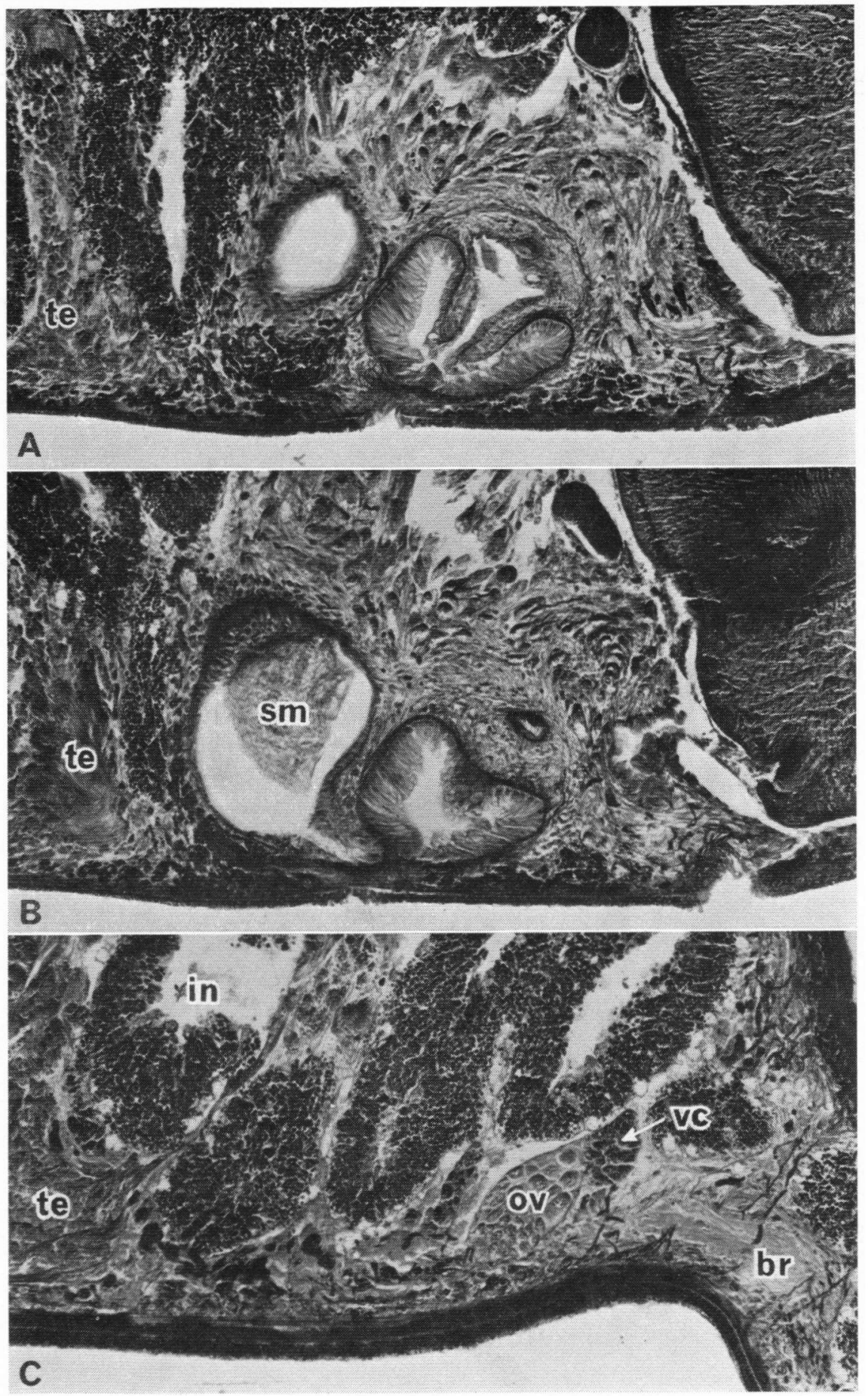

Fig. 3. Eviella bynesae gen. et sp. nov. A, sagittal section through the penis, $X 130 ; \mathrm{B}$, sagittal section through the "bursa", $X 130 ; C$, sagittal section through the ovary, $X 130$. br = brain; in = intestine; ov = ovary; sm $=$ sperm mass in the "bursa"; te = testis; vc = vitelline cells adpressed to the ovary. For further interpretation compare with fig. 2. 
the lateral nerve cords, just behind the brain. The oviducts arise from the anterodorsal side of each ovary and thus ascend vertically before curving ventrad and caudad towards the copulatory apparatus. Each oviduct enters separately the wall of the expanded female genital duct (bursal canal), and also dispatches a caudal branch to the hindmost vitellaria (fig. 2). Usually the oviducts are asymmetric in that the part entering the bursal canal may be much longer, and much higher, on one side than on the other (fig. 2).

A typical bursa copulatrix is not present. Instead the bursal canal, recognizable from its low nucleate and ciliated epithelium, overlain by circular and longitudinal muscles, is greatly expanded so as to form a sperm receptacle. At its ental end the wall of this sperm receptacle is modified (fig. 3B). Here the epithelium is unciliated and comprises very tall or papillose cells. The outlying musculature is greatly thickened and consists of intermingled muscle fibres of no one orientation. The whole complex is pierced by eosinophilic unicellular glands. This region appears to serve as an attachment zone for pyriform sperm masses that were seen in all the specimens examined (fig. 3B). These masses were not bounded by a wall or membrane of any kind and thus are not considered to be true spermatophores. The sperm receptacle, which is behind, and sometimes slightly lateral to, the male atrium opens into the latter just above the gonopore, and in this narrow region receives the opening of numerous shell glands (fig. 2).

The vitellaria are diffuse follicles scattered throughout the body, usually dorsally, from in front of the ovaries almost to the tail of the animal. A compact group of darkly-staining vitellaria is usually adpressed to each ovary, near the oviduct openings, and these may be comparable to the parovaria of higher planarians (Woodworth, 1891), but they are much smaller than those of most planariids. Elucidation of their status would require sections of material at various stages of maturation, but such material is not available to me.

Distribution. - Australia, Victoria, Howqua River about $50 \mathrm{~km}$ E.S.E. of the ski resort town of Mansfield (grid ref. 451415). Here the river is
3-4 $\mathrm{m}$ wide with fixed boulders and rocks, and some gravel. It flows fairly swiftly in the flatter part of the valley between deep slopes, and it is surrounded and overshadowed by tall forest. This is the type locality, and the only known locality, for this species. The specimens were collected on 26 January 1972 by Professor H. B. N. Hynes.

Etymology. - The species is named for Mary E. Hynes who deserves some credit for the valuable collections of planarians that resulted from her, and her husband's, expedition to Australia.

\section{DISCUSSION}

In recent years a number of retrobursal planarians have been described from freshwater habitats. Rhodax evelinae was described as a freshwater planarian from epigeal waters in Brasil (Marcus, 1946) and has been tentatively assigned to the family Dugesiidae (Ball, 1974a). And from caves in Mexico there have been described two species of Opistbobursa, $O$. mexicana and $O$. josephinae (see Benazzi \& Giannini, 1973; Benazzi, 1976), the former having been described independently by Mitchell \& Kawakatsu (1972). These species have been considered as marine relicts and therefore have been classified within the Maricola by their original authors.

The relationships of these forms have been discussed at length by Mitchell \& Kawakatsu (1972: 13) who concluded that whereas Rhodax evelinae and Opisthobursa mexicana appear to be each others closest relatives, and Rhodax should be accorded familial status, they could not be classified together in the same family because Rbodax evelinae possesses a ductus genito-intestinalis rather than an exteriorly opening bursal pore. Nonetheless, they regarded both as marine relicts, presumably derived independently from the same or different marine ancestors.

It seems probable that Eviella bynesae too, is a primitive direct descendent of marine ancestors and the temptation to unite all of these species into a single family is very real. Nevertheless such a family could be defined only on the basis of primitive characters, which in a strictly phylogenetic system is inadmissable. It is also true to say that the species of Opisthobursa have been assigned to the 
Maricola on the basis of primitive features and additional evidence of their maricolan nature is desirable.

In their general appearance the species of $R$ bodax, Opisthobursa, and Eviella share many similarities, especially the latter in their lack of eyes and all traces of pigment. Their general habit is the same, they have pharynges of the basic planarian type, and the oviducts and shell glands open into the bursal canal. There the joint resemblances stop. Unusual features of $E$. bynesae that are shared with $R$. evelinae are the fused testes, and the caudally branched oviducts which also are shared with a number of Australasian freshwater planarians of the genera Reynoldsonia and Spathula (Ball, 1974b, 1977). There are fewer features in common with the species of Opisthobursa. Both the species of Rhodax and of Opisthobursa differ from $E$. hynesae in their possession of a dorsal diverticulum of the bursal canal that receives the oviducts and shell glands, and in the presence of a spermexpellant pore in the bursa, opening to the intestine in $R$. evelinae and to the ventral surface in the Opisthobursa species. The latter condition is paralleled in a marine planarian, Oregoniplana opistbopora, from Pacific North America (Holmquist \& Karling, 1972). In this species the female genital duct runs posteriad from the atrium and opens to the exterior without forming a bursal sac.

Apart from the fully fused testes, the most singular feature of the new species relates to the female genital duct. At first glance there is what seems to be a large bursa copulatrix posterior to the penis. That it functions as a bursa copulatrix is evidenced by the fact that usually it is packed with sperm. But by its structure it cannot be a primary bursa; the epithelium is low and ciliated and clothed in strong muscle fibres. It seems that the primary bursa has been lost and its function has been taken over by the greatly expanded bursal canal (female genital canal). Such is the case also in Procerodes variabilis and Meixnerides armatus, two marine planarians from the southern hemisphere (Böhmig, 1902; Westblad, 1952).

The peculiar attachment zone for the sperm masses (fig. 3B) is without parallel in the aquatic planarians but appears similar to the condition found in a prosobranch mollusc Ceritbiopsis tuber- cularis (see Fretter \& Graham, 1962, fig. 192). In the mollusc, however, there is definitely a sperm-ingesting gland associated with the receptaculum seminis and the sperm are group-orientated before absorption. No evidence of these latter phenomena has been found in the slides of Eviella bynesae. In aquatic triclads it is well known that the sperm are usualy stored in the tubae of the oviducts, immediately behind the ovaries, and the bursa serves merely as a sperm receiver at copulation and for the digestion of excess sperm. In some species a spermatophore may be deposited. Sperm may be stored in a viable state for many weeks. Perhaps the sperm in E. bynesae are stored as attached masses on the wall of the female duct with the numerous glands serving to aid maintenance of its potency or viability.

The recognition that the "bursa" of this animal, receiving the separate oviducts, is really a greatly expanded female genital duct raises an interesting question. Do the expanded diverticula of the bursal canal of $R$. evelinae and of the Opisthobursa species represent the original female genital canal from which the terminal primary bursal sac has been lost? The loss of the primary bursa is common in marine planarians $(\mathrm{Ax}, 1956)$ but often it is later, in evolutionary terms, replaced by a secondary bursa, or bursae, as in the Uteriporidae and Bdellouridae for example (see Holmquist \& Karling, 1972; Ball, 1975). It is not impossible that the "bursae" of both $R$. evelinae and the Opisthobursa species are such secondary acquisitions, and already it is apparent that the histological structure of the bursa of $O$. mexicana is not quite like that of other aquatic planarians, and the peculiar bursal pore is not present in specimens not fully matured (Mitchell \& Kawakatsu, 1972: 10).

The many similarities with maricolan forms notwithstanding I decline to classify Eviella bynesae with the marine planarians. It is undoubtedly an old and primitive form, but its paludicolan nature is evidenced by the structure of the anterior sensory organs, the sensory fossae and ciliated pits. These are of a type quite unknown in the Maricola and yet very common in nearly all Australasian freshwater planarians (Ball, 1977). Eviella bynesae clearly belongs to the main evolutionary line that 
has diversified to give the majority of the Australasian forms and therefore it must be classified with them in the Dugesiidae. It is unfortunate that the new species is blind because I have attached great importance to eye structure as a defining character of the Dugesiidae (Ball, 1974b, 1974c), but the secondary evidence is sufficient to warrant its inclusion in this family.

\section{ACKNOWLEDGEMENTS}

It is a pleasure to thank Professor H. B. N. Hynes (Waterloo, Canada) for entrusting these valuable specimens to me. I also thank Professor C. H. Fernando (Waterloo, Canada) and W. D. Williams (Adelaide, Australia) for attempting on my behalf to recover further material from the Howqua River. The opportunity to study comparative material in the United States National Museum was obtained through the kindness of Dr. Roman Kenk, and Dr. Eveline Marcus made her slides of Brasilian material available to me. For all this help I am grateful. The drawings are the work of Maria Tran Thi Vinh-Hao whose labours I acknowledge with gratitude. The entire study was supported by operating grant A0016 of the National Research Council of Canada.

\section{REFERENCES}

Ax, P., 1956. Monographie der Otoplanidae (Turbellaria). Abh. math.-naturw. Kl. Akad. Wiss. Mainz, 1955: 499-796.

BALL, I. R., 1974a. A contribution to the phylogeny and biogeography of the freshwater triclads (Platyhelminthes, Turbellaria). In: N. W. RISER \& M. P. MORSE eds., Biology of the Turbellaria: 339-401 (McGraw-Hill, New York).

, 1974b. A new genus and species of freshwater planarian from Australia (Platyhelminthes, Turbellaria). J. Zool., Lond., 174: 149-158.

- 1974c. A new genus of freshwater triclad from Tasmania, with reviews of the related genera Cura and Neppia (Turbellaria, Tricladida). Life Sci. Contr., R. Ont. Mus., 99: 1-48.

,- 1975 . Contributions to a revision of the marine triclads of North America: the monotypic genera Nexilis, Nesion, and Foviella (Turbellaria, Tricladida). Can. J. Zool., 53: $395-407$.
- 1977. A monograph of the genus Spathula (Platyhelminthes, Turbellaria, Tricladida). Aust. J. Zool., Suppl. Ser., 47: 1-43.

BenAZZI, M., 1976. Opisthobursa josephinae, a new troglobitic planarian from Chiapas, Mexico. Atti Accad. naz. Lincei, Rendiconti, CI. Sc. fiz. mat. nat., (8) 59: 533536, pls. I-II.

Benazzi, M. \& E. Giannini, 1973. A remarkable cave pla. narian: Opisthobursa mexicana Benazzi, 1972. In: Sub. terranean fauna of Mexico, part II. Further results of the Italian zoological mission to Mexico, sponsored by the National Academy of Lincei. Accad. naz. Lincei, Problemi attuali di Scienza e di Cultura (Sez. Missioni ed Esplorazioni - I), Quaderno 171: 47.54, pls. I-IV.

BöHmig, L., 1902. Turbellarien: Rhabdocoeliden und Tricladiden. Ergebn. Hamburg. Magalh. Sammelreise, 3: 1-30.

FretTeR, V. \& A. Graham, 1962. British prosobranch molluscs: i-xvi, 1-755 (Ray Society, London).

Holmquist, C. \& T. G. Karling, 1972. Two new species of interstitial marine triclads from the North American Pacific Coast, with comments on evolutionary trends and systematics in Tricladida (Turbellaria). Zoologica Scr., 1: 175-184.

HyMaN, L. H., 1951. The invertebrates, 2. Platyhelminthes and Rhynchocoela: i-vii, 1.550 (McGraw-Hill, New York)

KenK, R., 1930. Beiträge zum System der Probursalier (Tricladida paludicola). Zool. Anz., 89: 145-162.

Marcus, E., 1946. Sôbre Turbellaria brasileiros. Bolm. Fac. Filos. Ciênc. Univ. S. Paulo, 11: 5-253.

Mitchell, R. W. \& M. Kawakatsu, 1972. A new family, genus, and species of cave-adapted planarian from Mexico (Turbellaria, Tricladida, Maricola). Occ. Pap. Mus. Texas Tech Univ., 8: 1-16.

Steinmann, P. \& E. Bresslau, 1913. Die Strudelwürmer (Turbellaria). In: H. E. ZIEGLER \& R. WOLTERECK eds., Monographien einheimischer Tiere, 5: 1-380 (W. Klinkhardt, Leipzig).

WEISs, A., 1910. Beiträge zur Kenntniss der australischen Turbellarien, 1. Tricladen. Z. wiss. Zool., 94: 541-604.

Westblad, E., 1952. Turbellaria (excl. Kalyptorhynchia) of the Swedish South Polar Expedition 1901-1903. Further zool. Results Swed. Antarct. Exped., 4 (1): 1-55.

WOODWORTH, W. M., 1891. Contributions to the morphology of the Turbellaria, 1: On the structure of Phagocata gracilis, Leidy. Bull. Mus. comp. Zool., Harvard, 21: 1.44 . 